\title{
Disciplinary Crisis and Curriculum Repositioning: A Case Study on the Sustainable Development of English Departments in China
}

\author{
Xiaozhou Zhou \\ School of English Studies, Shanghai International Studies University, China
}

Copyright $\bigcirc 2016$ by authors, all rights reserved. Authors agree that this article remains permanently open access under the terms of the Creative Commons Attribution License 4.0 International License

\begin{abstract}
The unprecedented expansion of English as a Lingua Franca has largely shaped the state of English language education worldwide, particularly in Asian countries where a number of countries used to be British colonies. With English being spoken as a second or foreign language in almost all Asian countries and required as an essential skill for nearly every profession, English majors, who in the past possessed the competitiveness of being proficient English users, are rapidly losing their advantages. English departments are criticized for developing graduates who can merely use English as a tool but lack critical, independent and innovative thinking skills. This phenomenon, significantly evident in China, is mainly caused by the outdated design of national curriculum for English majors. The present research takes the form of a case study in a Chinese university English department. Classroom observation and in-depth interviews are employed to investigate the problems of and solutions to the current curriculum. Participants believe that excessive language training has led to the weakening of English Language and Literature as an academic discipline and that a return to the humanities-oriented approach for future development of English departments should be adopted. A language plus liberal arts curriculum model is proposed and relevant issues regarding disciplinary construction are discussed. It is hoped that research questions in this study can be further explored with a larger sample elsewhere in China and that the findings could shed some light on the development of English departments in other Asian countries.
\end{abstract}

Keywords Curriculum, English Majors, China, Disciplinary Construction

\section{Introduction}

English Language and Literature (henceforth ELL) as a discipline has been continuously developing for a century in China and the debate over and the reform of the curriculum for it have never ceased. Every step of the curriculum reform for ELL seemed to accord to the necessity of China's social and economic development. Yet, the results were rather unsatisfactory, which yielded more criticism and future proposals. Nevertheless proposals for future reform are to a large extent based on experience instead of experiment. One of the common deficiencies of such proposals is that they lack first-hand investigation and consideration on the integral level of ELL across Chinese universities.

The global trend of English as a Lingua Franca has further stimulated English language education worldwide, particularly in Asia where the use of English in work environments has increasingly been regarded as a norm. With English language education being integrated into a country's general education, the direction and competitiveness of English majors become a critical issue which awaits urgent solution. When non-English majors are capable of communicating confidently in oral and written English, the training of English language skills is supposed to cease as the main aim of English departments, in which case a new and appropriate focus should be defined. This is a matter that concerns not only China but also almost every other Asian country.

This study sets out to explore the future development of ELL's curriculum from an empirical perspective. Instead of drafting plain guidelines based on discussions centred on past detours, as seen in previous literature regarding this topic, the current study aims to answer the research questions through classroom observation and in-depth interviews with teachers. It takes the form of a longitudinal case study which involves three participants and five skill-based and content-based courses. It is hoped that findings generating from this can provide a more tangible and insightful viewpoint with regard to the curriculum development of English departments.

\section{The Development of English Departments and ELL as a Discipline in China}

English as a major has developed to a point where it is no longer a homogeneous course but rather as a comprehensive 
collection of different types of courses taken throughout the four years of college study. Before the founding of The People's Republic of China in 1949, the educational system of western countries such as the UK and America was adopted by foreign language faculties in China. Within this system, students' knowledge and ability to appreciate English and American literature were emphasized and graduates were expected to become experts in teaching and researching foreign literature. The courses available to students were literature-based and there were no separate courses designed to improve language skills (Dai and $\mathrm{Hu}$ [1]; Wang and Gong [2]). However after 1949, the Chinese Ministry of Education modified the higher education system, encouraging universities to learn from those in the former Soviet Union, which resulted in the advocacy of Russian language education and hence the marginalization of English education in China (Dai and $\mathrm{Hu}$ [1]; Zhang and Dai [3]).

Since the 1950s, a distinct shift from the more literature-based teaching model as practiced in the UK and America to the skills-oriented Soviet Union model could be witnessed. The Soviet Union model highlighted the importance of skills training in foreign language education and was still being employed in the mid-1980s. During that time the old English literature departments were changed into English language and literature departments, as it is now. In this type of departments, apart from skill-based courses, students also follow content courses such as literature, linguistics and overviews of English-speaking countries ( $\mathrm{He}$ [4]; Jin [5]; Zhang [6]). English language education in China was to a large extent suspended during the Cultural Revolution (1966-1977). Following the 1978 Reform known as Opening-up, English Language Teaching regained its importance and over the past thirty years has been subject to constant restructuring and undergone numerous transformations (He et al. [7]; Zhang and He [8]).

The most recent Curriculum for English Majors which came into existence in 2000 states that the purpose of educating English majors is to cultivate them as intellectuals with not only solid English language skills but also extensive cultural knowledge. In the meantime they are expected to be capable of applying English language proficiently in translation, administration and research in the areas of foreign affairs, education, economy and trade, culture, science, and the military, as required by the social and economic advancement of the $21^{\text {st }}$ century. The aim is to produce interdisciplinary intellectuals (Teaching and Research Group of English High Education in China [9]).

The publishing and implementation of the current curriculum triggered heated debate over the prospects of English departments and the development of curriculum among academics in this field. First of all, the goal of cultivating interdisciplinary intellectuals was questioned. Even though it is understood that the market is in need of interdisciplinary intellectuals, scholars worry that the efforts made to achieve this goal are likely to weaken the characteristics of ELL as a discipline in the humanities area. Zhou and Fan [10] consider that the idea of interdisciplinary intellectuals creates an illusion for students, who may believe they can become experts in such relevant areas by taking these courses. Meanwhile the courses in English language skills, literature and culture are neglected. In the end, it is unlikely that such courses will be able to accommodate both elements successfully.

On the other hand, the results of cultivating interdisciplinary intellectuals for over 20 years reveal that graduates from these departments are not regarded as interdisciplinary intellectuals but intellectuals with their own specialties or enhanced English skills. Additionally, universities which retain interdisciplinary subjects such as Law and English, Tourism and English, Media and English within English departments are experiencing the hardship of lacking qualified teachers who can teach other subjects thoroughly in English (Hu and Sun [11]; Zhang et al. [12]).

In fact, cultivating interdisciplinary intellectuals was a reaction to the criticism that English department was becoming no more than a language centre which focused only on improving students' English language skills. This utilitarian point of view was due to the fact that after the founding of the P.R.C. there was an urgent need for individuals with English skills to support the economic development of the country. As a result the target of English departments at that time was determined by the need to export graduates skilled only in the use of English (He [4]; Huang [13]). ELL as a discipline was thus regarded as merely a tool. It was argued that the resulting excessive emphasis on language skills training at the expense of discipline nurturing broadened the gap between English majors and graduates from other humanities areas in terms of the structure of knowledge, profundity of thinking and analytical abilities (An [14]; Liu [15]). In short, there is a view the accomplishment of studying in an English department is not limited to the enhancement of the ability to communicate in English but more of the expanding of ideation, the restructuring of social and moral value and reconfiguration of personality (Wang [16]; Zhang [6]).

Since both approaches (skill training and interdisciplinary intellectuals) proved to be unsuitable for the development of English departments, the core issue that has emerged is the direction that should be taken next in order to improve the prospects of disciplinary construction for English departments. It is suggested that English departments should return to the humanities area and be devoted to cultivating liberal-arts-oriented English intellectuals. This type of intellectual is equipped with proficient English language skills, a wide scope of knowledge of humanities and other aspects, critical thinking ability, creativity, social responsibility and the ability to quickly fit into any type of profession (Hu and Sun [11]; Wang [16]; Zhang et al. [12]). The return of the humanities and the need to acknowledge English as one of the humanities disciplines and the call to introduce liberal arts subjects to the current curriculum has been echoed by various scholars (Dai and Zhang, [17]; Huang [13]; Liu [15]; Wang [16]; Zheng [18]).

The change of direction in disciplinary construction will 
inevitably lead to a change in the curriculum. One of the perspectives considers that English departments need to first establish the dominant status of English and American Literature, Linguistics and Studies of English-Speaking-Countries (including cross-cultural studies) and then in order to expand to the territory of humanities, a series of quality courses on liberal arts taught in English should be added (Hu and Sun [11]; Zhang and $\mathrm{He}$ [8]). Others recommend that liberal arts curriculum be introduced from the first year of university learning and be studied together with the skill courses (Wang and Gong [2]; Zheng [18]). There are also opinions advocating a thorough reform of the current curriculum by extensively reducing the number of skill courses and increasing the number of content ones so that English learning is accomplished through studying content courses such as linguistics, literature, European and American culture, philosophy and sociology (Huang [13]; Zhang et al. [12]). Despite abundant theoretical discussions, there has been little empirical evidence from first-hand data gathered from classrooms or teachers that supports or opposes such argument. To this end, the current study is set to probe into the issue of curricular construction for English departments through classroom observation and interviews with teachers, since it is believed that though theoretical exploration is essential in providing general proposals, classrooms are more likely to illuminate convincing and persuasive standpoints.

\section{Research Questions}

The current research aims to answer following questions regarding curriculum for English majors:

1. What are the problems with the current national curriculum for English majors?

2. Which direction should English departments in China take for future development?

3. In what way can the curriculum be improved or reformed?

4. What are the other issues concerning disciplinary construction that need to be solved, alongside the curriculum?

\section{Material and Methods}

The participants are three male teachers (Teachers A, B and C) from the English department in a Chinese university. They comprise a typical group of competent and qualified cases in terms of teaching ELL at tertiary level in China. Firstly, all received their Bachelor, Master and $\mathrm{PhD}$ education in prestigious universities in China and all of them have had experience of being visiting scholars in English-speaking-countries, which reflects the fact that their English language proficiency should be at a high level compared with other English teachers in Chinese universities as a whole. Secondly, they are working for a university which has a strong national reputation for ELL as a discipline, which to some extent justifies their abilities to make comments on the current curriculum. Thirdly, they have all been teaching for more than ten years. In addition, they are all mid-career, which implies that they are expected to be of a status where their understandings of their jobs, curricula, and disciplinary development have reached a stabilized and consolidated stage (Huberman [19]).

Two data collection methods were used: classroom observation and interview. Classroom observation ran from Week 1 to Week 16 of the summer term which lasted from September to January. Five different courses were observed: Advanced English, Introduction to Linguistics, American Literature, Western Philosophy, and British and American poetry ${ }^{1}$. A total of 96 lessons were observed and audio-recorded. Interviews were held with the three participants in Week 2, Week 9 and Week 16 respectively. Therefore, there were a total of six interviews, varying in length from 30 to 60 minutes.

The reason classroom observation was chosen as a data collection method was that it allowed the researcher to capture detailed dynamic in the classroom and as stated previously, classroom is considered as the best location to reflect issues regarding teaching and learning, if any. An open observation approach was adopted with no pre-determined observation protocol brought into the classrooms, since it was hoped that an open observation would leave more space for new thoughts and reflections being generated.

The first round of interviews aimed to obtain participants' views on English Language Teaching as a whole in China and a statement of their personal teaching beliefs and methods. The purpose of the second round of interviews was to understand participants' perceptions of the problems in current curriculum, suggestions on improvement or reform, and the future development of ELL as a discipline. The last round of interviews focused on a number of questions generating from classroom observation and follow-up questions from previous interviews. All interviewing data were subject to thematic analysis.

\section{Findings}

Classroom observation and a review of the audio-recordings of the lessons revealed a surprisingly large amount of Chinese spoken in both skill-based and content-based courses. The content of the Chinese spoken mainly centred on the provision of knowledge about Chinese literature, culture, philosophy and etc. as well as the comparison of such knowledge from the western and Chinese perspectives, which prompted the completion of time coding so as to obtain a specific and quantified picture of the language use behaviour mentioned above. Results from time coding are presented in the table as follows.

\footnotetext{
1 Teacher A taught Advanced English and American Literature; Teacher B taught Western Philosophy; Teacher C taught Advanced English and Introduction to Linguistics. Advanced English was a comprehensive skill-based course whereas the rest of the subjects were content-based.
} 
Table 1. Time Coding Results from Classroom Observation

\begin{tabular}{|c|c|c|c|c|c|c|}
\hline \multirow{2}{*}{} & \multicolumn{2}{|c|}{ Teacher A } & \multicolumn{2}{c|}{ Teacher B } & \multicolumn{2}{c|}{ Teacher C } \\
\cline { 2 - 7 } & $\begin{array}{c}\text { Advanced } \\
\text { English }\end{array}$ & $\begin{array}{c}\text { American } \\
\text { Literature }\end{array}$ & $\begin{array}{c}\text { Western } \\
\text { Philosophy }\end{array}$ & $\begin{array}{c}\text { British and } \\
\text { American Poetry }\end{array}$ & $\begin{array}{c}\text { Advanced } \\
\text { English }\end{array}$ & $\begin{array}{c}\text { Introduction to } \\
\text { Linguistics }\end{array}$ \\
\hline $\begin{array}{c}\text { Time coding } \\
\text { result 1 }\end{array}$ & 24.6 & 38.9 & 53.4 & 45.7 & 23.5 & 37.7 \\
\hline $\begin{array}{c}\text { Time coding } \\
\text { result 2 }\end{array}$ & 19.1 & 30.2 & 46.8 & 25.6 & 16.5 & 27.2 \\
\hline
\end{tabular}

As is seen in the table, time coding results showed a significant amount of L1 (Chinese) used in classes where English was required to be the working language. Furthermore, a considerable amount of time was spent on lecturing Chinese literature, culture, philosophy and etc. (in Chinese) which was not even part of the syllabi of the courses observed. Even if it might be regarded as understandable to integrate knowledge of Chinese literature, culture and philosophy in content-based courses such as American Literature, Western Philosophy, and British and American Poetry with a view to creating a comparative framework to help students achieve better understanding, it still remained confusing as to why such knowledge was also provided in skill-based courses where English language skills should be the focus.

Questions concerning the time coding results, together with the Research Questions, were asked during the in-depth interviews with the participants. It was discovered that the reason participants spent a significantly large amount of time in class speaking Chinese and lecturing Chinese literature, culture, philosophy and etc. was that they believed such knowledge was essential and should be included in relevant courses. However the current curriculum did not reflect the inclusion of courses related to Chinese literature and culture, participants had to take the initiative to provide students with this type of knowledge even if it was not specified in lesson objectives. Teacher A explained for his language use behaviour:

I am aware of the amount of Chinese I speak in classes. I do not think it is necessary to speak English all the time because most of the time I prefer to input knowledge about Chinese literature and culture to the students and it will be strange if I use English in this situation.

Teacher $\mathrm{C}$ also commented:

As English majors, it is not sufficient to learn western literature and culture exclusively. Students should be exposed to viewpoints from various sources and only in this way can they improve their critical acumen and independent thinking abilities. That's why I tend to include knowledge about Chinese literature and culture even in Advanced English course, as long as the contents in the textbook served as a prompt.

Two major problems with the current curriculum that could be identified from the interviews were: lack of literature/culture-based courses and excessive emphasis on language skills training. Teacher A looked back at the curriculum for English majors in Tsinghua University before 1949:

The curriculum was designed by $\mathrm{Wu}$ Mi who graduated from Harvard University in America. Therefore he consulted the curriculum employed there. Students were reading extensively during the first year, which provided them with the basis for developing their English language proficiency as well as ability in understanding and appreciating literary texts. When they moved on to the 3rd or 4th year, they focused on studying Shakespeare, Milton and Chaucer etc. In that case, teachers were not responsible for improving students' language skills so they could concentrate on teaching literature. Unfortunately it is impossible for us to do so now.

The excessive emphasis on language skill courses was criticized by all the participants as a critical problem with the current curriculum. Teacher B argued that the unnecessary amount of time spent on teaching language skills and the lack of elements on culture and humanities in the curriculum was due to the insufficient cultural awareness of the people responsible for establishing the curriculum. He explained:

I do not think there is a clear guide embedded in the current curriculum. On the one hand, it realises that the mastery of English language skills should not be the only purpose of education in this department. I assume it has recognised the fact that if language competence is seen as the sole teaching and learning objective, ELL as a discipline will face serious challenges. On the other hand, these realisations are not reflected in the curriculum. I think the people who design the curriculum have not achieved an appropriate level of cultural awareness and sensitivity of knowledge about humanities. This curriculum is too old to possess an accurate reflection of the current situation.

With regard to the direction that English departments in China should take for future development, all participants suggested a return to the humanities-oriented approach which was adopted during the early $20^{\text {th }}$ century. They believed that a humanities-oriented approach would be more effective in helping ELL rebuild itself as an academic discipline and more likely to develop the so-called cultured citizens with a wide scope of knowledge, cultural awareness, creative and critical thinking abilities. Teacher $\mathrm{C}$ claimed that the concept of cultivating interdisciplinary intellectuals, 
as stated in the current curriculum, had led the discipline of ELL in the wrong direction:

It weakens the characteristics of this discipline, because on the one hand time spent on language skills training is eliminated to make way for the other subject courses but on the other hand, students' achievements in these subjects such as economics, media, politics and etc. is incompetent compared with those majoring in these subjects. A return to the humanities-oriented approach would allow our students to avoid rote learning of pure language skills, read more extensively, think more actively and achieve a deeper understanding of different cultures and civilisations.

A shift of direction is inevitably going to lead to a change in curriculum. A language plus liberal arts model is proposed by participants. The table below provides a synthesis of the structure of a working curriculum based on the suggestions gained from all the participants.

Table 2. Proposed Curriculum Structure for English Majors

\begin{tabular}{|c|c|c|}
\hline \multirow[b]{2}{*}{ Year 1} & $\begin{array}{l}\text { Language } \\
\text { courses }\end{array}$ & $\begin{array}{c}\text { listening, speaking, reading and general } \\
\text { writing }\end{array}$ \\
\hline & $\begin{array}{l}\text { Liberal arts } \\
\text { courses }\end{array}$ & $\begin{array}{c}\text { Chinese History and Culture; Ancient and } \\
\text { Modern Chinese Language; Intercultural } \\
\text { Communication; and etc. }\end{array}$ \\
\hline \multirow[b]{2}{*}{ Year 2} & $\begin{array}{l}\text { Language } \\
\text { courses }\end{array}$ & interpreting, translation, academic writing \\
\hline & $\begin{array}{l}\text { Liberal arts } \\
\text { courses }\end{array}$ & $\begin{array}{l}\text { History of British Literature; History of } \\
\text { American Literature; Poetry; Drama; } \\
\text { Various selective courses on Chinese and } \\
\text { western literature }\end{array}$ \\
\hline \multirow[b]{2}{*}{ Year 3} & $\begin{array}{l}\text { Language } \\
\text { courses }\end{array}$ & interpreting, translation, academic writing \\
\hline & $\begin{array}{l}\text { Liberal arts } \\
\text { courses }\end{array}$ & $\begin{array}{l}\text { Western Civilisation; Western Philosophy; } \\
\text { Art History; Various selective courses on the } \\
\text { history and culture of English-speaking } \\
\text { countries }\end{array}$ \\
\hline \multirow[t]{2}{*}{ Year 4} & $\begin{array}{c}\text { Liberal arts } \\
\text { courses }\end{array}$ & Intensive reading of a number of classics \\
\hline & & Dissertation \\
\hline
\end{tabular}

Undergraduates' future profession possibility is a key issue when it comes to the consideration of disciplinary construction. In the past, students with proficient English language skills were able to obtain satisfactory posts upon graduation, due to the high demand for competent language users required by the market. Nonetheless, with the expansion of English language education in China, students who can speak fluent English are losing their competitiveness, which was the point argued by the participants in this study. However, what future does a language plus liberal arts curriculum hold for English majors? Teacher B stated:

I believe they are suitable for every profession and they have many choices. When they are well educated in liberal arts and have developed a certain level of cultural awareness, they can work in education, politics, media, journalism, marketing, management and etc. because I believe that most of the skills that the current occupations require are the ability and dimension of self-retrospection. And every skill or piece of knowledge demanded by a particular profession is floating on a type of culture. If culture is neglected, I don't think we are able to make a correct judgment when a decision has to be made.

Apart from the reform on curriculum, there were other issues concerning disciplinary construction suggested by the participants which were waiting for solution. The points they made could be summarised as below:

- A humanities-oriented approach for ELL development requires qualified teachers, which means a sustainable and focused teacher recruitment scheme should be established.

- The reform on curriculum will result in a fundamental change of teaching pedagogy. Current teachers, particularly those with little liberal arts background, should be re-trained so that they are capable of integrating language and content teaching.

- Once the learning outcomes are determined, departments should allow teachers to have certain freedom within the curriculum to better adapt to their individual research interests.

\section{Discussion}

Although all the participants in this study agreed with a language plus liberal arts model as the future development direction of English departments in China, their considerations seemed to be based on different reasons. According to Teacher $\mathrm{A}$, the reason for advocating this model is due to misconceptions held by other disciplines who regard the English department as merely a tool which only provides English language training to students. This argument of Teacher A coincides with the views of some researchers (An [14]; Liu [15]; Wang [16]). These scholars, together with Teacher A believe that being misunderstood by other disciplines along with excessive emphasis on English language skills training have weakened the characteristics of ELL as a humanities discipline.

As a proposed means of correcting this misunderstanding, cultivating interdisciplinary intellectuals in English departments was promoted and established as a national policy in the official curriculum. However, Teacher $\mathrm{C}$ argues that this policy has been proved to be unsuccessful. His viewpoint is supported by recent literature ( $\mathrm{He}[4] ; \mathrm{Hu}$ and Sun [11]; Zhou and Fan [10]) which argues that the implementation of this policy has created a disciplinary crisis for English departments. Since the reduced amount of time devoted to the learning of English language and literature while studying a limited number of courses from relevant disciplines such as economics, media, politics etc. is not helpful in turning the graduates into experts in these areas, students are likely to become less competent in the job market. 
Though the model of language plus liberal arts is proposed by all three participants, they seem to differ in what exactly this model entails. Teacher A's perception of liberal arts education is connected with the curriculum used before 1949 when a literature-based model was adopted from the west. Hence his ideas about liberal arts focus almost exclusively on literature. Considering that Teacher A has been teaching and researching American Literature for over two decades, it can be argued that his perspective is affected by his research interest and disciplinary identity.

Teacher B speaks of the need for language plus liberal arts model from the perspective of nurturing students in humanities and raising their cultural awareness. He believes that liberal arts subjects are helpful in enlightening students in literature, culture and philosophy. This enlightenment should not be restricted to humanities majors but expanded to students of all backgrounds because everybody is expected to be equipped with a certain level of cultural awareness before they embark on any profession. It can be seen that Teacher $\mathrm{B}$ describes a much broader picture. Liberal arts education from his point of view is not accomplished through purely teaching literature or culture courses but rather through approaching literary, cultural or philosophical texts, discovering their realistic applications, and relating them to current society. Through doing so, students' historical and cultural awareness is raised and their critical acumen is strengthened.

The problem of the current curriculum hindering the development of critical thinking skills for English majors and the idea of returning to the humanities area for English departments were also identified in recent literature (Liu [15]; Wang and Gong [2]; Wen et al. [20]; Zhang [6]; Zhang and He [8]; Zhang et al. [12]). Although previous literature indicates the need to develop students' critical thinking, analytical and reasoning skills by teaching relevant liberal arts subjects, it does not suggest anything more than adding liberal-arts-related-courses for the students. In this study, Teacher $\mathrm{C}$ takes this much further by pointing out that making these courses available serves as only the first step in a liberal arts education and that teaching approaches and methods matter much more than the contents. Teaching these courses should not aim to ensure the mastery of the knowledge by students but focus on the development of certain important skills, and it is the teachers' responsibility to enlighten and encourage the students in class as much as possible.

Two issues have emerged from these teachers' interpretations of the language plus liberal arts model. Firstly, even though it is a language plus liberal arts model by name, they seem to avoid discussing the importance of language education at all. It can be argued that although they acknowledge the place of language education within the curriculum, they believe the liberal arts aspect is more crucial as it represents the characteristics of this discipline and differentiates it from other disciplines. Secondly, their different interpretations of this model reflect that even within such a small sample of three people, there exist noticeable differences. Hence it can be presumed that the differences would be much greater if the interviews were conducted with a larger sample.

Furthermore, as classroom observation and interviewing results indicate, participants place a significant emphasis on the element of Chinese literature and culture in the curriculum, which resonates with the criticism towards English majors for lacking knowledge of Chinese culture and cross-cultural awareness, compared with those from other humanities departments (Liu [15]; Sun and Jin [21]; Xiao et al., [22]; Zhang and He [8]; Zhang et al. [12]). Studying Chinese literature and culture is regarded as fundamental and essential by the participants for the purpose of not only developing students' intercultural communication abilities but also reinforcing the awareness of their own cultural identity. In the proposed curriculum structure represented in Table 2, courses concerning Chinese language, culture and intercultural communications are suggested to be arranged in the first year of studies with a view to connecting with the knowledge of Chinese language and literature that students have gained in secondary schools.

More importantly, implementing the language plus liberal arts model inevitably triggers the issue of qualified teachers. In this context, qualified teachers refer to those who are experts in one subject in humanities and meanwhile able to deliver lessons in fluent English. It can be expected that such qualified teachers are difficult to find in China where English is taught as a foreign language and students from humanities departments in universities learn all their subjects in Chinese. This issue has been addressed in previous literature where it is suggested that universities can look for potential candidates from graduates with a doctoral degree in humanities abroad and a Bachelor degree in English, send teachers to study in English-speaking-countries on a regular basis, organise research groups and seminars to guide and supervise teachers in teaching and researching ( $\mathrm{He}$ [4]; Wang [16]; Hu [25]; Liu [26]). Regarding this issue, Teachers A and B in this study have shared some initial thoughts on building an undergraduate scheme to develop candidates for future teachers. They propose that exceptional talents can be identified from among undergraduates who have demonstrated their interests in humanities. They can then be funded by the department or the university to study towards a doctoral degree in one of the disciplines in humanities in an English-speaking-country and promise to come back to teach relevant humanities subjects. This proposal, though lengthy, seems more feasible and reliable than other short-term measures, provided that a fair and effective mechanism of selecting potential candidates is established in advance.

\section{Conclusions}

To summarize, through classroom observation and in-depth interviews, this study discovers the problems existing in the current curriculum for English majors, 
suggests the direction of returning to a humanities-oriented approach for English departments' future development, proposes a language plus liberal arts curriculum model and discusses other issues (e.g. developing qualified teachers) concerning ELL disciplinary construction. An element of Chinese literature and culture in the curriculum is repeatedly emphasized and critical acumen is viewed as one of the most crucial skills that English majors are expected to acquire.

Core findings from the study concentrate on the proposed language plus liberal arts education model for English majors which seems to be a desirable and effective means of keeping the characteristics of the ELL discipline as part of the humanities area. Nevertheless, since previous discussion has revealed that teachers tend to be affected by their own research interests and disciplinary identities when formulating their views of the model, any liberal arts course included in the future curriculum will need to include an appropriate balance of history, literature, culture, philosophy and etc. in order to avoid disproportionate stress on one particular aspect.

It should be noticed that there is a limit to the generalisation that a case study involving three participants could produce. Moreover, the setting of this study is in a leading English department of a Chinese university with a prestigious reputation for foreign language teaching, which indicates that the findings may only be relevant to top-ranked English departments. Considering the vastly uneven geographical development of English language education in China, the requirements set in the proposed curriculum need to be accordingly lowered in terms of course diversity, difficulty and learning outcomes for universities of different levels. This should be taken into account when a new curriculum for English majors is being designed, since one single national curriculum is unlikely to guide the development of all English departments in China.

\section{Acknowledgements}

This work was supported by the Research Center for Foreign Language Strategies in China under grant WYZL201409, and Shanghai International Studies University in China under grant QYGBYJ15ZXZ.

\section{REFERENCES}

[1] Dai W, Hu W. On the Development of Foreign Language Education in China. Shanghai Foreign Language Education Press, Shanghai, 2009.

[2] Wang Y, Gong L. Strengthening the reform of curriculum for English majors based on liberal arts education. Journal of Qilu Normal University, 2015; 30(2):28-31.

[3] Zhang X, Dai W. Analysis of the change of the curriculum for the undergraduate programme of English language and literature in Chinese universities. Foreign Languages and
Their Teaching, 2010; 1:1-5.

[4] He L. Comparative study of curriculum settings of English literature major among British, American, and Australian undergraduate courses. Journal of Jilin Teachers Institute of Engineering and Technology, 2013; 29(1): 51-52.

[5] Jin L. Transforming the English Curriculum for Humanistic Education - A Report on the Reform at Department of English, BFSU. Foreign Language Teaching and Research, 2010; 42(3): 176-183.

[6] Zhang Y. On cultivating critical thinking skills related to curriculum teaching and assessment for English majors. Journal of National Academy of Education Administration, 2014; 4: 54-57.

[7] He Q, Huang Y, Qin X, Chen J. Teaching assessment of English in China tertiary education over the past 30 years. Foreign Language Teaching and Research, 2008; 40(6): 427-432.

[8] Zhang R, He Y. Principles and strategies of curriculum design for foreign language majors: A discourse analysis perspective. Chinese University Teaching, 2015; 1: 45-49.

[9] Teaching and Research Group of English High Education in China. Curriculum requirements for English Majors. Foreign Language Teaching and Research Press, Beijing, 2010.

[10] Zhou X, Fan Y. Objective clarification and positioning on cultivating interdisciplinary intellectuals in English departments. Foreign Language World, 2010; 4:36-66.

[11] $\mathrm{Hu}$ Q, Sun Y. On strengthening humanistic education in the English language curriculum. Foreign Language Teaching and Research, 2006; 38(5): 243-247.

[12] Zhang L, Wu Y, Jin L, Sun Y, Zhou Y. Reform of curriculum for English majors and construction of an interactive mechanism for teacher development: A case of English department at BFSU. Foreign Languages and Their Teaching, 2013; 3: 30-33.

[13] He Z. On the discipline construction of English language and literature departments. Journal of Foreign Languages, 2003; 2: 46-50.

[14] Huang Y. Inevitable reform on the curriculum for English language and literature departments - On the absence of critical thinking skills. Foreign Language World, 2010; $1: 11-16$.

[15] An C. The impact of improving curriculum for English majors on undergraduates' core competitiveness in career planning. Education and Career. 2011; 9: 160.

[16] Liu J. The introduction of cultural element in curriculum for English majors. Heilongjiang Researches on Higher Education, 2010; 11:152-154.

[17] Wang Z. Internationalization, localization, and globalization On course design and arrangement of English major in China. Contemporary Foreign Language Studies, 2014; 1:31-35.

[18] Dai W, Zhang X. Reflections on the undergraduate programme of English language and literature in China. Foreign Language World, 2007; 4: 2-11.

[19] Wang S. Strengthening the discipline construction of undergraduate programme of English language and literature. Foreign Language and Their Teaching, 2001; 2:42-43. 
[20] Zheng Y. Reform on the curriculum for English majors and cultivation models for creative intellectuals. Foreign Languages and Their Teaching, 2006; 8:33-36.

[21] Huberman M. On teachers' careers: Once over lightly, with a broad brush. International Journal of Educational Research, 1989 ; 13(4): 347-362.

[22] Wen Q, Wang H, Wang J, Zhao C, Liu Y. Comparison on the critical thinking skills between English majors and undergraduate from other disciplines in arts and humanities. Foreign Language Teaching and Research, 2010; 42(5):350-355.
[23] Sun Y, Jin L. Reform on content courses in the curriculum for English majors. Foreign Language Teaching and Research, 2010; 42(4): 303-305.

[24] Xiao L, Xiao D, Li Y, Song Y. Aphasia of Chinese culture in English education in Chinese universities. Foreign Language Learning: Theory and Practice, 2010; 1: 39-46.

[25] $\mathrm{Hu}$ Z. Reflections on English Language Education in China. Foreign Language Research, 2002; 3:5-9.

[26] Liu Y. On the curriculum for English language and literature departments in Chinese universities. Foreign Language World, 2000; 3:12-17.

\footnotetext{
${ }^{i}$ Average amount of time (\%) spent on speaking L1 (Chinese) in each class over 16 weeks

ii Average amount of time (\%) spent on providing knowledge about Chinese literature, culture, philosophy and etc. in each class over 16 weeks
} 